\title{
Children's Exploration of Physical Phenomena During Object Play
}

\section{Citation}

Solis, Lynneth. 2017. Children's Exploration of Physical Phenomena During Object Play. Qualifying Paper, Harvard Graduate School of Education.

\section{Permanent link}

http://nrs.harvard.edu/urn-3:HUL.InstRepos:33797223

\section{Terms of Use}

This article was downloaded from Harvard University's DASH repository, and is made available under the terms and conditions applicable to Other Posted Material, as set forth at http:// nrs.harvard.edu/urn-3:HUL.InstRepos:dash.current.terms-of-use\#LAA

\section{Share Your Story}

The Harvard community has made this article openly available.

Please share how this access benefits you. Submit a story.

\section{Accessibility}




\section{Children's Exploration of Physical Phenomena during Object Play}

Qualifying Paper

Submitted by

S. Lynneth Solis

April, 2015 


\section{Acknowledgements}

I want to express my deepest gratitude to the children and teachers who participated in this study. I cherish the opportunity to witness and join the wondrous play worlds that they created together. May my science incorporate as much play as their play incorporates science.

I am eternally grateful to my committee members, Tina Grotzer, Paul Harris, and Eileen McGowan, for their wisdom and continual support. Many thanks to Amani Hayes-Messinger, Kaley Curtis, and Maleka Donaldson Gramling for their contributions to the analysis of my data. Their insights and feedback throughout the process were integral to the way I organized and made sense of the results.

This work is dedicated to my family, especially my husband Antonio Berdugo, my parents Saida Solis and Jose Manuel Solis, and my sister Jacqueline Solis-Yee, for their unconditional love. Their encouragement and prayers carried me through the arduous process of writing this paper.

This research was supported in part by National Science Foundation, Grant No.DRL-0845632 to Tina Grotzer. All opinions, findings, conclusions or recommendations expressed here are those of the author and do not necessarily reflect the views of the National Science Foundation. 


\section{Table of Contents}

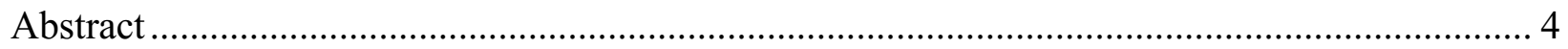

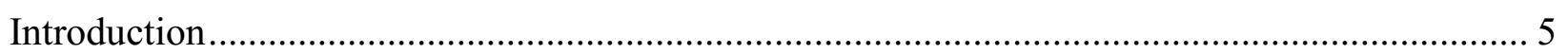

Physical Concepts in Preschool ..................................................................................... 7

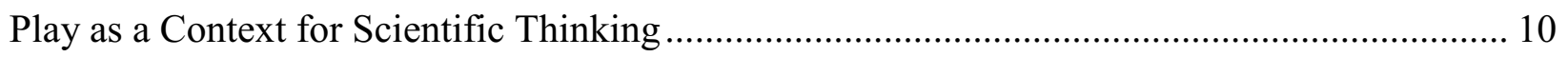

Object Play and the Exploration of Physical Science Concepts ............................................ 12

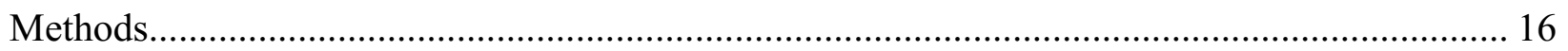

Participants \& Research Sites ................................................................................. 17

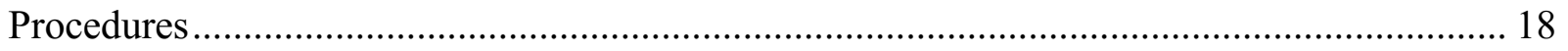

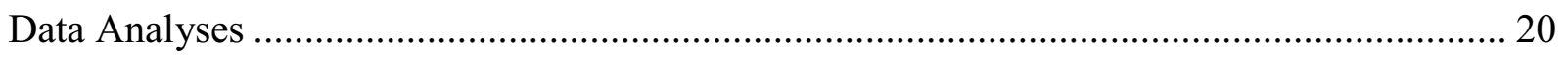

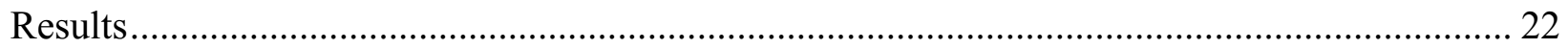

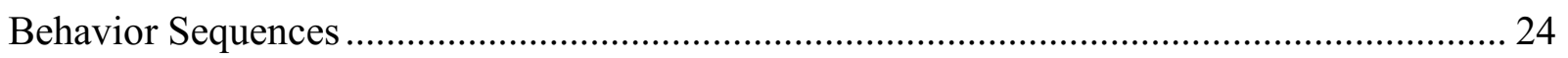

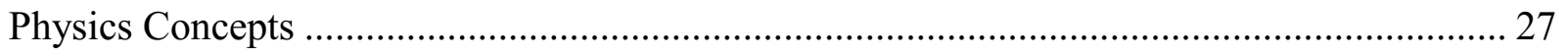

Physics Concepts: Simple Machines ........................................................................ 32

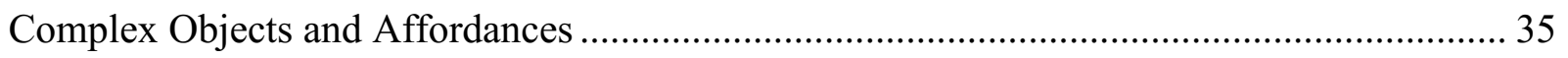

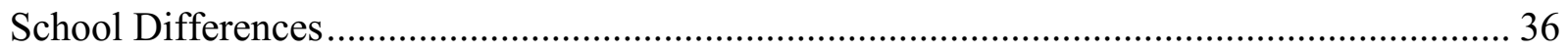

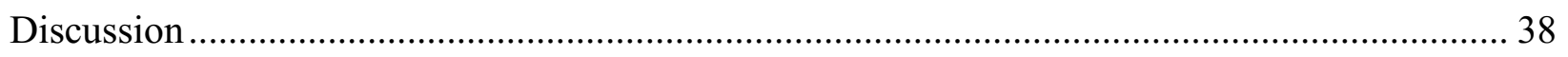

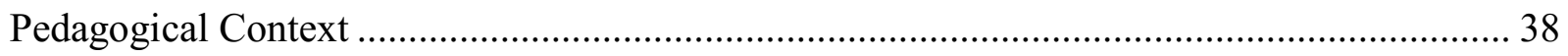

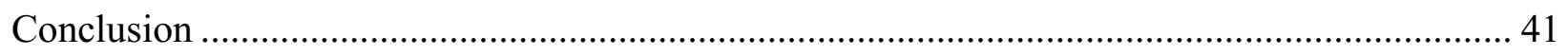

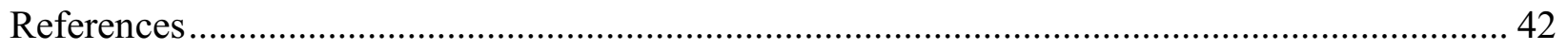

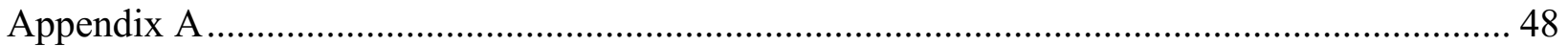




\begin{abstract}
Researchers propose that experiencing and manipulating physical principles through objects allows young children to formulate scientific intuitions that may serve as precursors to learning in STEM subjects (Gur, 2011; Evangelou et al., 2010; Stoll et al., 2012). This may be especially true when children discover these physical principles through object affordances during play (Garvey, 1990; Van Meeteren \& Zan, 2010). The present study investigated preschoolers' spontaneous exploration of physical phenomena during their object play experiences. It consisted of biweekly naturalistic observations of 20 children's free play, carried out over eight weeks in two Northeastern United States preschools. Results demonstrated that children encountered a variety of physical concepts, including magnetism, forces, energy, tension, friction, and simple machines, as they engaged in spatial-mathematical activities, planned and executed play sequences, problem-solved, and explored with objects available in their classrooms. The findings offer insights into the physical phenomena available to children through object play and how these opportunities can be used to support children in reasoning about the physical world.
\end{abstract}




\section{Children's Exploration of Physical Phenomena during Object Play}

\section{"Play is the highest form of research."-Albert Einstein}

Anthropological and experimental research has established that play is prevalent in children's lives across cultures (Callaghan et al., 2011; Sawyer, 2002; Schwartzman, 1976), and many researchers, parents, and teachers believe play experiences are beneficial for children (Singer, Golinkoff, \& Hirsh-Pasek, 2006). Different categories of play-from dramatic play to games and sports - are thought to be associated with physical, cognitive, and socio-emotional competencies (Pellegrini, 2009). Nevertheless, despite its general appeal and after decades of cross-disciplinary research on the subject, there is still much about play and its role in development that is unknown (Lillard et al., 2013).

One area of play that deserves further attention is the relationship between object play and young children's development of scientific reasoning. Object play refers to children's incorporation and manipulation of toys, everyday utensils and tools (e.g., pots and pans), natural materials (e.g., sticks, rocks, shells), and other found objects (e.g., beads, cloths) into their play activities (Bjorklund \& Gardiner, 2010). Although object play may occur within a make-believe episode, it is different from dramatic play, in that the play behaviors focus on handling, exploring, and acting on an object as opposed to simply using the object as a prop in a play storyline. As Hughes (2012) puts it, during object play "children experience the world by exploring the tactile and cognitive properties of objects" (p. 83). This form of play constitutes $10 \%$ to $15 \%$ of all behaviors in Western early childhood settings (Smith \& Connolly, 1980 as cited in Bjorklund, 2012) and has been shown to be related to higher levels of problem-solving skills (e.g., Sylva, Bruner, \& Genova, 1976), creativity (e.g., Johnson, Christie, \& Wardle, 2005), 
and spatial-mathematical reasoning (Caldera et al., 1999). Other scholars have suggested the possible role of object play in helping children discover and explore causal relationships and mechanisms embedded in objects (Bjorklund \& Gardiner, 2010).

Scientific reasoning refers to the knowledge, investigatory strategies, and logic of science (Zimmerman, 2010), and it appears that when it comes to physical phenomena, when children play with objects, they engage in the types of theory building and hypothesis testing that scientists engage in (Gopnik, 2012). Early developmental scholars like Piaget (1930) proposed that through concrete experiences with objects, children reason about the physical world and develop abstract notions of causality. One set of concepts ubiquitous during object play entails the physical principles (e.g., force, motion, and energy) that operate when children manipulate objects (Bairaktarova, Evangelou, Bagiati, \& Dobbs-Oates, 2012). Researchers propose that encounters with these principles through tangible objects can assist young children in formulating abstract ideas that can serve as precursors to learning in STEM subjects (Gur, 2011; Evangelou, Dobbs-Oates, Bagiati, Liang, \& Young Choi, 2010; Stoll, Hamilton, Oxley, Eastman, \& Brent, 2012).

An extensive body of research has investigated how children's scientific reasoning may be related to the ways they manipulate and explore objects, but much of this research has been conducted in laboratory settings using objects operated by researchers and has focused mostly on the ways that children make causal judgments as opposed to how they explore specific physical concepts (e.g., Gopnik \& Sobel, 2000; Legare, 2012; Schulz, Gopnik, \& Glymour, 2007). Descriptive studies of object play in everyday environments are incredibly necessary (Pellegrini, 2009) and critical if we are to understand the ways that children learn intuitively about the physical world through objects. The present study was conducted to investigate preschoolers' 
spontaneous exploration of physical phenomena during object play experiences in their classrooms. $^{1}$

Before reporting on the study methods and results, I set the theoretical foundation for this investigation. First, I briefly review literature that supports the claim that preschoolers can learn about physical phenomena in everyday pedagogical contexts. Second, I make a link to literature that establishes a relationship between play and children's development of abstract scientific ideas. Third, I discuss how object play may be particularly unique in inciting preschoolers to reason about physical phenomena.

\section{Physical Concepts in Preschool}

Dating back to Piaget (1930), researchers and educators have been interested in young children's emerging physical knowledge-what some scholars have called intuitive physics (Wilkening \& Cacchione, 2010) — and how these early understandings are translated into the formal knowledge of physics later in development. Researchers have investigated children's understanding of a number of physics concepts, including time and speed, the trajectory of moving objects, force and weight, volume and density, and temperature (for a review see Wilkening \& Cacchione, 2010). Over the decades, this work has illustrated that young children "organize their physical experiences in narrow but coherent explanatory frameworks" (p. 62) and that children are quite capable of interpreting and reasoning about basic physical principles (Vosniadou, 2002). This work has also shown the challenges children may face in making sense of physical concepts, how robust certain misconceptions about physical phenomena can be, and

\footnotetext{
${ }^{1}$ Historically, "play" and "exploration" have been starkly contrasted in the play literature as two categorically different constructs (Hutt, 1966). Play is typically defined as an activity with no inherent purpose that is enjoyable in itself, while exploration is described as serious, goal-orientated investigation of objects or situations and their features, often elicited and maintained by the degree of novelty and complexity of the object or situation (Pellegrini, 2009). Although there is room for a healthy debate on the topic of whether or not exploration constitutes play, this debate goes beyond the confines of the theoretical framework for the present study. In the remainder of this paper, I use exploration and play interchangeably to refer to a constellation of playful and investigatory behaviors that may be important for learning about objects and the physical laws that children encounter as they play with these objects.
} 
the importance of pedagogical interventions to help children reconcile their early conceptions with more complex scientific explanations (Hadzigeorgiou, 2002). For instance, Vosniadou (2002) found that while kindergarteners described force as internal to objects and affected by weight, size, and position or as acquired within a moving object, only $9^{\text {th }}$ graders incorporated the Newtonian ideas of gravitational force and the force of push/pull in their explanations. Nevertheless, even in cases when young children struggle to achieve accurate scientific explanations, they appear incredibly attuned to the physical principles in their environment (Gur, 2011).

Children's ability to engage with physical science concepts has been vividly illustrated by examples of formal and informal preschool activities that relate to STEM content. Gross (2012) argued that children can learn about buoyancy, density, displacement, and porosity by playing and experimenting with sinking and floating objects or about cohesion and surface tension by exploring bubbles. Gross described that objects (e.g., measuring cup, droppers, colanders, spoons) are instrumental for engaging and facilitating children's exploration of these phenomena. In an observational study, Fox (1997) analyzed the physics principles that emerged when young children played with swings — described in the study as life-sized pendulums — and found that children experimented with balance, force, gravity, resistance, and resonance as they worked to "align their own center of gravity with that of the swing" or as they applied force "in the same direction as the swing" in order to move (p. 5).

Researchers have paid attention to the pedagogical factors that support children's scientific learning in preschool. Hadzigeorgiou (2002) found that preschoolers demonstrated an understanding of mechanical stability in building a tower on an inclined plane using cans of various sizes and weights when they had previously played with similar materials in a structured 
and guided manner. Drawing from Kamii and colleagues (1993) and Copple et al. (1984), Hadzigeorgiou reasoned that physical knowledge (such as mechanical stability) is most accessible to preschoolers when their experiences involve objects, actions on these objects, and observable reactions on the part of the objects that children can compare and contrast. Hadzigeorgiou's study highlighted not only that children can gain an implicit understanding of physical phenomena but that this learning is most effective when objects are available and teachers can scaffold the learning. Along the same lines, Larsson (2013) described "science as an emerging form of knowledge in preschool" and carefully documented the myriad encounters that children had with friction in a Swedish preschool (e.g., playing with a tomato on a table or trying to get up a snowy hill) that presented opportunities (and missed opportunities) for teachers to scaffold children's investigation of friction. According to Larsson, young children are able to develop an intuitive understanding of the physical world as they encounter objects and situations in their daily work and play in preschool settings, and that teachers can leverage these opportunities to build "bridges" to scientific understandings (p. 390).

What can be gathered from the existing literature is that opportunities to bridge concrete experiences and abstract physics ideas are pervasive in the preschool environment: on the playground, when using water and sand tables, and in the block corner, for example (Gur, 2011). As has been reviewed, these opportunities often entail play with objects. The research also suggests that the goal of preschool experiences with physical science "is not to teach [explicit] scientific concepts, principles, or explanations. It is, rather, to provide opportunities for the child to act on objects and see how objects react, to build the foundation for physics" (Kamii \& DeVries, 1993, p. 12). The present study, then, contributes to the growing interest in incorporating physical science in the preschool curriculum by illustrating how play—and 
specifically play with objects—offers a meaningful context in which children organically encounter opportunities to reason about physical phenomena. As discussed next, it appears that the spontaneous, flexible, generative nature of play invites children to explore, reason, and learn about abstract ideas that may be fundamental to later science thinking.

\section{Play as a Context for Scientific Thinking}

What is it about play that invites children to engage in the kind of behaviors and thinking that may inform their development of scientific ideas? Henricks (2008) described play as a "laboratory of the possible" (p. 168). This metaphor seems to suggest that as young children play, they invent, discover, evaluate, and make sense of the causal patterns and scientific phenomena they encounter in flexible ways that have meaning beyond the play scenario; it suggests that children can derive ideas from these play experiences that can inform their interpretation of the real world.

Cognitive developmental researchers have examined the actions, explanations, and questions children employ as they explore novel toys and physical phenomena in lab studies, and their findings suggest that children explore the physical world through play (Gopnik, 2012). These researchers have found that when children encounter novel objects and phenomena in playful situations, they ask questions (e.g., Legare, Mills, Souza, Plummer, \& Yasskin, 2013) and entertain various hypotheses about their use (e.g., Legare 2012, 2014), formulate "experiments" and play more to disambiguate possible causes or effects (e.g., Cook, Goodman, \& Schulz, 2011; Schulz \& Bonawitz, 2007), and learn about the causal structure of objects through their own interventions (e.g., Sobel \& Sommerville, 2010). For instance, in an experimental study, Legare (2012) found that when preschoolers encountered outcomes inconsistent with their prior experiences of whether or not particular blocks made a pair of boxes 
light up (in the classic "blicket detector" paradigm), their exploratory behaviors were related to the causal explanations they provided. Children who provided causal function explanations about why a box lit up or not (e.g., "The blicket is not working anymore. It is broken," "There isn't energy power inside,' “All out of batteries') also played more, produced more variable play, and engaged in more spontaneous hypothesis-testing behaviors than their counterparts. Children's manipulation and experience with the objects seemed closely linked to the causal explanations they were developing.

In a similar "blicket detector" design study, Cook, Goodman, and Schulz (2011) presented preschoolers with a music box that would be activated by placing a pair of toy beads on the box; in some cases the beads were stuck together and in others the beads could come apart. Children were invited to play with the box and use the beads to make it go. Cook et al. found that when it was unclear which beads made the music box work (as when the beads were stuck together), children engaged in a series of exploratory behaviors (or "experiments") that allowed them to isolate which bead caused the box to turn on. The authors' conclusion was that the exploratory actions that children demonstrate in play are likely the same they exercise and develop when making sense of ambiguous physical phenomena in everyday situations.

The evidence shows that children prove quite adept at formulating possible causal explanations, testing various mechanisms, and devising appropriate solutions for situations they experience during play (at least when this occurs in lab settings). This points to children's ability to enact their existing ideas about how things work and make new connections between their play worlds and the real world. In the next section, I discuss why this may be especially the case when children play with objects. 


\section{Object Play and the Exploration of Physical Science Concepts}

In her book "Evocative objects: the things that we think with," Turkle (2007) describes objects as provocations for ideas, feelings, and memories. According to this view, objects are conduits for making sense of ideas much bigger and more abstract than the tangible, concrete properties of the objects themselves. This is exactly the idea framing the present investigation of children's object play and their reasoning about scientific phenomena. Developmental literature supports the notion that objects help to "instantiate and exemplify more abstract notions" and “[assist] in building more abstract thinking” (Evangelou et al., ๆ 4). Classical developmental scholars like Piaget, Froebel, and Montessori described objects as provocations for children's inquiry into the physical realm. Froebel, the father of the kindergarten movement, believed that playing with objects had the potential to "introduce children to the physical forms and relationships found in nature" (Provenzo, Jr., 2009, p. 87). More recently, commenting on Fleer (2010), Larsson (2010) argued that "children are more able to learn science concepts if they get opportunities to explore physical objects and are not presented with correct scientific explanations at the outset" (p. 379).

Young children are surrounded by objects in their environment that provide different affordances, features, and, functions that elicit manipulation, construction, and pretense (Bjorklund \& Gardiner, 2010). ${ }^{2}$ Affordances refer to the "perceived and actual properties of [an object]...that determine just how the [object] could possibly be used" (Norman, 2002, p. 9). Ecological psychologists posit that object affordances and the ways individuals manipulate these

\footnotetext{
${ }^{2}$ This claim about the availability of objects is one that has been mostly corroborated in Western, industrialized cultures and middle-income families. It is important to note that the presence of objects in a child's environment can be affected by context-specific factors, such as culture and cultural beliefs about play, family or school economics, pedagogical philosophy, and social structure (Power, 2000). Thus, the present research may be most pertinent to children's experiences in Western societies. That said, by and large, objects and artifacts (as broadly construed; not specifically toys) continue to be central to the human experience, are likely to feature to some extent in young children's lives, and can mediate children's interactions with the physical environment (Cole 1998; Cole \& Gajdamaschko, 2007).
} 
affordances inform their perceptions of an object's underlying physical properties and the understandings they abstract from them (Gibson, 2000). The affordances that children discover and explore can help them generate evidence to formulate understandings about the actions and events that occur as they are manipulating objects during play. Gur (2011) explains it as follows,

Children investigate the properties of objects through hands-on exploration. For example, materials such as cardboard tubes, lengths of plastic rain gutters, balls, and objects with wheels help children develop notions about the position and motion of objects. For another example, playing with measuring cups, funnels and eyedroppers foster the understanding of volume, weight, gravity and force (p. 940).

Object properties, thus, appear to invite children to reason about intangible concepts within a tangible space.

One area of study that illustrates the development of abstract knowledge through object play is the literature on children's play with blocks, staple manipulatives found in most preschool classrooms in the United States. Children's play with these simple, three-dimensional geometric building shapes has been linked to the development of convergent and divergent problem-solving skills (Pepler \& Ross, 1981), spatial language (Ferrera, Hirsh-Pasek, Newcombe, Golinkoff, \& Lam, 2011), logico-mathematical knowledge (Kamii, Miyakawa, \& Kato, 2004), and spatial visualization abilities (Caldera et al., 1999) in young children. For example, Caldera et al. (1999) conducted in-depth observations of 60 preschool children's structured and unstructured play with blocks and assessed the relationship between particular building behaviors and children's spatial skills. Caldera et al. found that complexity of building strategies and interest and involvement in play activity were related to spatial visualization (i.e., ability to make mental manipulations of spatial information) and perceptual field independence (i.e., ability to focus on relevant features of an object outside of context). Although they acknowledged that their findings are not sufficient to establish a causal link, Caldera et al. suggested that the pattern of results was 
"consistent with the hypothesis that experience in play activities influences children's visualspatial skills" (p. 870).

Casey et al. (2008) tested the effect of two block-building play interventions on kindergarten's performance on three spatial measures (i.e., block building, block design, and mental rotation). Compared to the control group, children in the intervention conditions scored higher on the spatial reasoning assessments (e.g., built structures with more three-dimensional features or more successfully copied a two-dimensional image with a set of blocks), thus supporting the idea that specific play behaviors with the blocks can lead to benefits in reasoning abilities. Similar results have been found in children's development of mathematical and engineering concepts through block play (e.g., Kamii, Miyakawa, \& Kato, 2004; Park, Chae, \& Boyd, 2008; Samara \& Clements, 2009; Van Meeteren \& Zan, 2010).

Brophy and Evangelou (2007) found when building with blocks, "young children employed details of physical properties to allow them to create increasingly complex designs that worked within the governing properties of physics” (as cited in Van Meeteren \& Zan, 2010, ๆ 9). Similarly, Van Meeteren and Zan (2010) described that when building ramps and pathways with blocks, children practiced engineering design and incorporated math, science, and technology knowledge and skills, all within the nonsequential context that characterizes play. Thus, as children plan and execute the construction of block structures within play—by stacking and balancing blocks, classifying them by color or shape, and comparing the relative size of different components of their structures - they appear to be engaging in cognitive exercises that foster spatial-mathematical reasoning and can facilitate later academic performance (Ferrera et al., 2011). For example, Wolfgang, Stannard, and Jones $(2001,2003)$ found that complex block play 
in preschool (as rated on the Lunzer Five Point Play Scale) had a significant relationship with math achievement measures in middle and high school.

Garvey (1990) explained that "objects serve as a link between the child and his environment" (p. 41), and this appears especially true as children observe physical phenomena in the course of their play. Playing with blocks is only one example of this link between the child and the environment but there are many others. Children can encounter all kinds of physical phenomena - from playing with gears to testing out impromptu balances - that may engage them in reasoning about unseen forces and mechanisms that are fundamental to other complex scientific concepts that they will encounter in the real-world and classroom settings. Perhaps not unlike the tinkering of scientists, in playing with objects, children observe phenomena that call for explanations, which they try to formulate (either implicitly or explicitly) by testing object properties and structure (Van Meeteren \& Zan, 2010). Through the interaction with objects, young children uncover the possible functions of things that may tell them about scientific concepts that undergird these functions. When these play experiences can be guided in ways that highlight important physical properties, children may begin to build a repertoire of scientific notions that they can refer to as they interpret physical phenomena in the world (Hadzigeorgiou, 2002).

From the literature reviewed, we can conclude that during object play children encounter physical phenomena and, guided by object affordances and adults, are able to explore and reason about these phenomena in ways that interact with their growing understanding of the physical world. How this happens in everyday play experiences is the focus of the present study. Importantly, this study does not aim to determine the actual scientific conceptions that young children formulate but rather to identify the opportunities embedded in play experiences with 
objects that can foster an understanding of the physical world. Knowing what kinds of physical phenomena emerge naturally as children explore objects will offer insights into how object play may be related to young children's scientific reasoning more broadly. The study addresses the following research questions:

1. What behavior sequences do preschoolers engage in as they manipulate objects and make sense of physical phenomena during play?

2. What types of physical science phenomena emerge as preschoolers explore object affordances through their object play?

Exploring these questions will offer insights into the physical phenomena available through object play and how adults can utilize these moments as opportunities to discuss and explore physical concepts with them. That said, this study does not claim to characterize the play experiences of children across all early childhood settings but rather to present a picture of children in a particular context, as elaborated below.

\section{Methods}

Play is best understood within the contexts and settings that elicit and sustain it. Although we have gained a wealth of information about children's play as well as the development of causal and scientific reasoning through behavioral studies (some of this evidence reviewed above), these experimental approaches seem to overlook the unprompted nature of play. Smith (2010) explains that, "Regarding incentives, an important criterion for play is that it is unconstrained and done for its own sake. Therefore, artificial (constrained or experimental) situations are in danger of destroying an important characteristic of play" (p. 13). For this reason, it was critical that the methodology used in the present study allow children to play as freely as possible while their interactions with objects were documented and allow for patterns in their 
behaviors to emerge as they were observed over time. ${ }^{3}$ Thus, the study entailed naturalistic observations in preschool classrooms and emic and etic data analyses looking for recurring themes that addressed the research questions.

\section{Participants \& Research Sites}

Participants in the study were 20 children (ages 3-5) enrolled in two private preschool classrooms in the greater Boston area, with 10 children in each classroom. Although more children were present during classroom observations, only those who received parental/guardian consent were included in the observations. The sample (13 female, 7 male) represented an ethnically diverse group of children from middle-class to upper-middle-class families.

The schools differed in specific pedagogies but both had an explicit commitment to providing children with free playtime and had an expressed emergent curriculum that allowed for flexibility in the activities and content covered during the school day. School A was a privately run children's preschool program located in a suburb of Boston. ${ }^{4}$ The free play observations occurred in a dedicated playroom that had a play loft and shelves filled with books and play objects in labeled plastic bins. Each morning, the lead teacher put out a limited number of play objects that were available for children to play with as they arrived to school. The object selection often followed children's interests and curricular themes (e.g., castles). Once the free play hour had passed, children transitioned to circle time in a different room of the school. School B was a university-affiliated children's center located in a city just north of Boston. The preschool classroom was an open-format space separated into different areas using tables and bookshelves as partitions. Free play occurred in different stations around the room where

\footnotetext{
${ }^{3}$ This is not to say that experimental manipulation or intervention has no place in teasing apart the relationship between children's play and the reasoning they develop through and from these experiences. In fact, mixed-methods may be quite appropriate for investigating the complex relationship between play and development and will be employed in follow-up studies.

${ }^{4}$ Pseudonyms are used to refer to the school sites and children in this study.
} 
teachers set out play objects. For example, there was a water table, a light table, a block corner, and a play loft where objects were rotated every day. Children transitioned to and from free play during the morning and afternoon periods of the program.

The objects available in both classrooms were strikingly similar. Both classrooms had extensive sets of blocks, other building materials, and magnetic wood train sets. They also had objects that lent themselves more to dramatic play: dress-up materials; replicas of real-world objects, such as play food or trucks; and dollhouses and castles. However, these dramatic play objects were also used for object-oriented play. Finally, both classrooms had a number of more complex objects or sets of objects, such as a play crane and marble run equipment, that provided multiple entry points for children to explore interesting phenomena. These complex objects are discussed further in the results section.

\section{Procedures}

The study was conducted over a two-month period with a total of 14 one-hour visits per classroom (four familiarization visits and 10 data collection visits). This long-term involvement allowed me to witness a diversity of play situations and consider alternative hypotheses about object play experiences as I recorded my observations and impressions over time. The careful recording of behaviors provided detailed, rich data that helped to reveal a "picture of what is going on" as children played (Maxwell, 2005, p. 110). Furthermore, having two school sites provided opportunities for comparisons between sites to check whether patterns of observations were corroborated or refuted across settings (Maxwell, 2005).

I arranged to attend the classrooms during times in the day when the likelihood of observing children playing freely with toys and other objects would be maximized. Observations took place during the first morning hour in School A and during both morning and afternoon 
periods at School B on a consistent weekly schedule (approximately, two visits per week in each classroom, excepting snow days and other scheduling conflicts). During the first four familiarization visits to the classrooms, I did not formally collect data but rather interacted with the children to build rapport, became acquainted with the play environment to help guide my observations, and made my presence in the classroom as routine as possible to avoid disturbing children's play or unduly influencing their behaviors.

Data collection took place over the next 10 visits. The purpose of these observations was to document children's spontaneous exploration of physical phenomena during play with objects. During my visits, I walked around the classroom, observing children as they played and maintained detailed field notes of the kinds of objects they used and how the objects were being used in play. Following observational procedures described by Trawick-Smith (2010), I moved from one play area to another, observing children's activities for five minutes at a time. This method of observation ensured that recordings were systematic and representative of the variety of object play activities children engaged in. During my focus in each area, I identified the children playing; documented the objects they used; and recorded their actions and any verbal exchanges or narratives that provided context for their behaviors. Given that children played individually or in small pods, it was possible to record the behaviors of several children in a given area. The observations focused on instances when children were investigating and manipulating object properties (e.g., pulling, banging, building) rather than using objects as dramatic play props. For example, children were recorded building a castle with blocks but were not recorded pretending to put a princess doll to sleep on a (block) bed.

Data consisted of expanded field notes and digital video recordings, which served as alternative sources for data triangulation (Maxwell, 2005). Depending on the set up of the 
classroom, the video recorder was placed in one location that captured the whole classroom (School A) or was carried along to the different play areas (School B), being mindful to reduce any disturbance to children's play. Because of the differences in the setup of the play area in the two schools, the nature of video data collected varied slightly: videos from School A covered the entire play room, capturing most children's behaviors at once, and videos from School B covered play actions in different areas of the room, capturing the behaviors of a few children at a time.

During the data collection phase, written and voice-recorded memos of hypotheses, insights, and puzzles that emerged during the observations were developed which helped to address the research questions and guided data analyses described next.

\section{Data Analyses}

Field notes and videos were coded for two overarching categories: children's behaviors and the physical science concepts that arose through children's actions. The first phase of data analysis entailed emic, open coding of the data paying attention to children's behaviors and emergent themes across observations that pointed to physics concepts. Emic analyses are employed to discover emergent patterns of reasoning or behavior that are not predetermined based on the existing literature but that might nonetheless be informative in interpreting the data (Charmaz, 2002). The author analyzed the entire field notes corpus. To ensure the reliability of the emic analysis, a second coder with limited knowledge of the research hypotheses but with basic science training employed the same open coding process on $50 \%$ of the video data, which was equivalent to five visits per school that were chosen for their representativeness of the object play experiences observed. Excluded data included visits where the majority of the play observed constituted dramatic play (e.g., children pretended to be princesses and knights) or the majority of time was spent doing a teacher-led activity (e.g., a science project). 
During emic analysis, coders identified particular types of behavioral sequences that seemed pervasive in children's play (e.g., construction) and possible physical concepts (e.g., friction, tension, force) that were being enacted through children's activities. For example, in both classrooms, children had access to a magnetic train set where the different train pieces connected through magnets. Children spent time building the train track and matching up pieces to ensure that they fit together correctly. These types of constructing behaviors and others where children paid attention to spatial configuration, position, direction/orientation, proportion, or alignment were labeled as "spatial-mathematical behaviors." Using this same train set, children's manipulation of the trains and their experience of connecting the trains became an emergent code labeled "magnetism," indicating that children were experimenting with the phenomenon of attracting and repelling magnetic forces.

Emergent themes and categories that came up in both the field notes and video data were compared, discussed, and elaborated and discrepancies in interpretations were resolved. Although emic analysis entailed first impressions of "what might be going on," emergent categories were compared to existing literature on young children's play behaviors (e.g., Caldera et al., 1999) and learning of introductory physics concepts (e.g., Gross, 2012; Gur, 2011; Stoll et al., 2012). Agreed-upon and vetted categories were compiled into a coding scheme (Appendix A) used in a second phase of etic, top-down coding applied to the same video data used in emergent coding to determine relative frequencies and patterns of behaviors across the research sites.

During etic coding, a primary coder scored videos using Atlas.ti qualitative analysis software, deciding on instances to be coded and applying the coding scheme. ${ }^{5}$ As coding progressed, code descriptions and scoring rules were clarified and revised in conversations with a

\footnotetext{
${ }^{5}$ Given the facility of pausing and reviewing videos both emic and etic analyses of video data captured all children and all actions viewable within the camera frame.
} 
second coder. Data were scored iteratively to reflect the latest decision rules until coding was finalized. To establish reliability of the coding scheme, the second coder scored $20 \%$ of the data and applied the finalized coding scheme to predetermined instances identified by the first coder. Reliability was assessed at $86 \%(\kappa=.85)$. Any disagreements in scoring were discussed and recoded until there was $100 \%$ agreement in all categories. A review of all coded instances was conducted to ensure that all scoring reflected the final coding scheme and rules.

\section{Results}

Emic and etic analyses revealed a number of patterns that elucidated the kinds of behaviors children engaged in with objects and the science phenomena that emerged as children played. A total of 776 instances of behavior sequences $(n=312)$ and physics concepts $(n=464)$ were identified in the scored video data. ${ }^{6}$ There were more coding instances captured at School A $(n=526)$ than School B $(n=250)$, due to the positioning of the camera - given the set up of the classrooms and where the camera could be placed videos from School A covered the entire play room, capturing most children's behaviors at once, and videos from School B covered play actions in different areas of the room, capturing the behaviors of a few children at a time. Relative frequencies of the behavior sequences that children employed when manipulating different objects and the scientific phenomena that seemed to emerge during these interactions are summarized in Table 1. Overall, spatial-mathematical (42\%) and planning and executing behaviors (38\%) accounted for the majority of behavior sequences scored. The frequency of different physical concepts was distributed across different categories, with magnetism (23\%) forces $(15 \%)$, and balance (11\%) representing the most common categories-importantly, the frequency of magnetism was higher at School A as further considered below. Detailed

\footnotetext{
${ }^{6}$ More than one code could be applied to any given excerpt of the video data, thus the instances here may have overlapped.
} 
descriptions of each of the behavioral sequences and physical concepts categories along with illustrative examples from observations are discussed next.

Table 1. Frequencies (percentages) of object play behavior sequences and physics concepts across the two research sites.

\begin{tabular}{lrrr}
\hline \multicolumn{1}{c}{ Categories } & $\begin{array}{c}\text { School A } \\
(\boldsymbol{n}=526)\end{array}$ & $\begin{array}{c}\text { School B } \\
(\boldsymbol{n}=\mathbf{2 5 0 )}\end{array}$ & \multicolumn{1}{c}{ Total } \\
& & \\
\hline Behavior Sequences & & \\
Spatial-Mathematical & $88(40 \%)$ & $42(45 \%)$ & $130(42 \%)$ \\
Planning and Executing & $94(43 \%)$ & $26(28 \%)$ & $120(38 \%)$ \\
Problem-Solving & $23(11 \%)$ & $13(14 \%)$ & $36(12 \%)$ \\
Exploratory & $14(6 \%)$ & $12(13 \%)$ & $26(8 \%)$ \\
Total & $219(100 \%)$ & $93(100 \%)$ & $312(100 \%)$ \\
& & & \\
Physics Concepts & & & \\
Magnetism & $92(30 \%)$ & $15(10 \%)$ & $107(23 \%)$ \\
Forces & $52(17 \%)$ & $19(12 \%)$ & $71(15 \%)$ \\
Balance & $29(9 \%)$ & $20(13 \%)$ & $49(11 \%)$ \\
Gravity & $21(7 \%)$ & $22(14 \%)$ & $43(9 \%)$ \\
Energy & $6(2 \%)$ & $20(13 \%)$ & $26(6 \%)$ \\
Friction & $12(4 \%)$ & $8(5 \%)$ & $20(4 \%)$ \\
Tension & $11(4 \%)$ & $6(4 \%)$ & $17(4 \%)$
\end{tabular}

Physics Concepts: Simple

Machines

Wheel and axle

Ramps and Inclined Planes

$38(12 \%)$

$9(6 \%) \quad 47(10 \%)$

Levers

$14(5 \%)$

$26(17 \%)$

$40(9 \%)$

Pulleys

$22(7 \%)$

$0(0 \%)$

$22(5 \%)$

$10(3 \%)$

$12(8 \%)$

$22(5 \%)$

Total

$307(100 \%) \quad 157(100 \%) \quad 464(100 \%)$ 


\section{Behavior Sequences}

As can be expected, children engaged in myriad behaviors as they played with toys. They pushed, pulled, stacked, rolled, threw, held, and examined objects. They focused on singular objects to explore their multiple functions and combined objects to build structures. A systematic analysis of these behaviors yielded a number of different but not mutually exclusive categories of behaviors, behaviors that seemed to point to various modes of approaching and interacting with materials. These were almost never discrete actions but rather series of actions that seemed to point to similar intent or end goal, thus the label of behavior sequences. This is not to say that the behavior sequences reported here were all the categories of behaviors observed but they were behaviors that seemed to be repeated across school contexts and observations.

The most common category of behavior sequences observed was spatial-mathematical behaviors $(42 \%)$. The category name was chosen to indicate the types of behaviors that have been shown in the literature to foster spatial-mathematical reasoning. As children played with objects, they constructed with them, they fit them together, and connected them, paying attention to their spatial configuration, position, direction, and alignment. As discussed, there is a rich literature elucidating the benefits of playing and constructing with blocks but from the observations, it appears that similar spatial skills are being exercised through actions using a variety of objects, as illustrated in the following excerpt.

Isabel builds the train track by putting one piece in after the other, aligning the appropriate shapes to snap the pieces in place, and building the track from two directions to form a loop. She tries to connect one piece that has a slight upward curve but has trouble fitting it in until Oscar walks over and helps her to insert it. Isabel pulls off this piece and replaces it with another one as she continues to build. She is close to finally connecting the train track from both sides and closing the loop, but before doing so, she opens up enough space to add one final track piece. ${ }^{7}$

\footnotetext{
${ }^{7}$ Italicized text indicates that the excerpts have been taken from the field notes.
} 
The careful work that Isabel demonstrated in picking the pieces that would fit together and being able to execute the appropriate spatial configurations that would eventually lead to a completed train track loop was evident in children's play with a variety of toys, from Lincoln Logs, wooden blocks of all shapes and sizes, and Legos to magnetic trains and shapes, cardboard and plastic tubes, and Tinkertoy sets.

These spatial-mathematical behaviors also demonstrated planning and executing actions (38\%). Although they did not always announce what their plan was, children appeared intent on a particular goal to achieve a finished product. Their behaviors seemed intentional and sequenced, and once they arrived at their end goal (e.g., closing a loop of the train track) their attention seemed to shift to a different object or aspect of their construction. This seems contrary to the typical definitions of play as having no end goal; however, within the flexible play environment, it appears that children were content working toward completing certain tasks that they had set for themselves. In the excerpt above, Isabel kept going back to the plastic tub where train tracks were held to retrieve the pieces that would allow her to finish building the track. She continued on this task until the loop was completely closed. There were interruptions to her process, as she interacted with other children or briefly played with other objects, but she kept coming back to the track until it was completely finished. Similarly, Rushaan and Bradley carefully connected track pieces, adding one after another until they completely enclosed the circuit. "We did it!" exclaimed Rushaan, suggesting that they had accomplished something they had intended to do all along. Hope announced that she was building a "booby trap," and executed this plan as she built a structure with colorful wooden cubes, even despite several major collapses of her structure.

Hope is building two columns with colored wooden cubes on the floor. She has four cubes in each column and one rectangular piece placed across both columns. Hope tries to build on top 
of this structure. She puts a triangle on top and then moves it to the side in order to add another triangle next to it. She puts a log on top of the two triangles and tries to continue building. The structure falls and she exclaims, "Oh!" and then goes right back to building. The structure falls again and she goes right back to building again.

Hope's reaction of continuing to build despite the setbacks she encountered, and especially her focus on trying to figure out how to utilize the different shapes to build up, also demonstrated another category of behavior sequences labeled problem-solving behaviors (12\%). This category referred to instances where the children encountered situations that required figuring out what needed to change or be fixed in order to proceed with a play sequence or predetermined plan. In these circumstances, children seemed to be trying to figure out a solution to a problem they encountered as they played. For example,

Rushaan is building a square structure with Lincoln Logs but he finds a piece that doesn't quite fit within his existing structure. He examines the piece, flips it, pushes it down, looks for a different piece, and goes through different potential matches until he finds the one that fits snuggly and completes the "room where the baby ninja dog sleeps."

This kind of problem-solving behavior required the ability to determine a desired outcome, and plan and execute a series of steps to achieve this outcome, not to mention the spatialmathematical reasoning required when building as Rushaan did. Of course, this is not to say that children necessarily identified the situation as a problem or were frustrated by the process. Given the context of play, they seemed to enjoy the challenge of learning about the object characteristics to figure out how to best resolve the hiccups they encountered.

One way that children seemed to learn about objects' properties and features was through all sorts of exploratory behaviors (8\%). Children were clearly fascinated by object properties and proactively investigated what objects were able to do so as to include these objects in their play. As already illustrated, when having to match up logs, train tracks, or wooden blocks, children paid close attention to the makeup of objects and examined them to determine how to best fit 
them into the existing play sequences. This happened most markedly when introduced to new or unfamiliar items. For example,

Emma is immediately enthralled by the pulley that the teacher introduced. She says, "This is so amazing. What does this machine do?" Emma seems very intent on figuring out what it does and even looks at the accompanying directions for it. The teacher demonstrates what the pulley can do and says, "This is what it does." Emma continues looking at the pulley instructions for the pulley and putting the pulley pieces together accordingly. "Up and down," she says as she pulls the pulley string from one side to the other around the pulley wheels... "It's nothing. It's a machine," she tells another child who is also curious about this new object. Emma tries to pull the string onto the middle wheel by pulling it down from the other two top wheels, and tells another child what they need to do to get the pulley working. The string falls off and Emma says, "Wait, it broke." She tries to use another string.

After some continued exploration, Emma moved on to tying a string around a stuffed animal and pulling it around the carpet, testing the acoustics of a plastic tube, and playing with the marble run. However, having now explored the pulley, she came back to playing and experimenting with it in subsequent sessions when it was placed out.

As is evident in the overlap of examples across the different behavior categories and the fluid transitions from one description to the next, the various play behaviors occurred in tandem, illustrating the complex ways in which children come to know and play with objects.

\section{Physics Concepts}

As children manipulated objects in the ways described above, certain types of physical principles became apparent in their interactions with the objects. ${ }^{8}$ Magnetism $(23 \%)$ was a prevalent phenomenon and during the duration of the study visits was almost entirely experienced through the use of the magnetic train set, although other magnet building sets were also present on different days. Magnets were common in both classrooms and the train set, in particular, often took primacy whenever it was put out. ${ }^{9}$ Children experienced attracting and

\footnotetext{
${ }^{8}$ Please see Appendix A for the definitions of the scientific concepts discussed here.

${ }^{9}$ As is discussed later, the fact that the train set was put out more days during observations in one classroom than the other seems to account for some differences between the two schools in the frequency of instances of magnetism.
} 
repelling forces as they built long lines of train cars by connecting the magnets or used one train to move another at a distance by taking advantage of the repelling force. They appeared quite used to the attracting and repelling forces and were able to name the phenomenon as they experienced it.

Casey dumps all the trains from the container onto the carpet. She connects two trains together with the magnet and then connects a third truck piece. "This guy has a magnet," she explains as she connects the third piece.

Children seemed fascinated by their ability to link and unlink the magnets at will and by their ability to test the strength of the connections by creating train lines that were up to 15 train cars long. They pulled and pushed the trains along the wooden train track and even lifted their long train structures off the tracks to move to a different location. Emma, for example, lifted her train structure made up of seven cars and the magnets were able to hold together suspended in the air for a few seconds until they gave out and collapsed to the floor.

Children also took their long trains from the track onto the floor and back, which allowed them to experience changes in friction (4\%). For example,

Robert starts building a line of trains connected by the magnets on the carpet. He pulls the line apart to add another train, and then starts pulling the train structure around the room. The first and second trains disconnect as he pulls; he picks up the first piece and attaches it again. He continues pulling the trains around the room, "Coming through!" The front piece disconnects again and he puts it back on. He pulls the train onto the wooden track, slowly adding and reconnecting the pieces as they come up. He pulls the train around the track and then pulls the line off the track onto the carpet and continues pulling it around the room.

In this excerpt, not only was Robert playing and testing the power of the magnets, but he was also experimenting with different forms of resistance. While pulling the trains along the wooden track required almost no effort, keeping the trains connected as he pulled them around the carpet — which added resistance — required additional care to avoid having the whole thing pull apart. Children had access to many materials that allowed them to experience varying levels of 
resistance as they manipulated two surfaces that came into contact. In the following excerpt, Emma demonstrates her effort for managing and controlling friction as she tried to "ski" on the carpet.

Emma is invited by a classroom friend to pull out wood blocks for skiing. Emma puts the blocks that her friend has already pulled out back on the shelf and pulls out longer ones for skiing. She says, "I know some long blocks for skiing." She puts the blocks side-by-side, stands on them, and pretends to tie them. She slides them on the carpet carefully and slowly shuffles forward on them. She takes shorter blocks, steps on them, and pretends to tie them. She slides them forward as she stands on them. She takes even shorter blocks, stands on them, and slides forward. She's then called over for snack.

Instances like the ones described above, where children obviously encountered and manipulated the phenomenon of friction, were present throughout children's object play. However, there were many other instances where children encountered the concept of friction where the phenomenon was less obvious (e.g, the trains moving smoothly on the train tracks). Analysis of this code focused on cases where friction was a salient aspect of children's play_for example, as they experienced a change in friction (e.g., moving from the track to the carpet) or the resistance became the focus of their play (e.g., countering the resistance as they moved the object across the floor). Thus, the relative frequencies reported in Table 1, represent this more particular notion of friction as opposed to the more prevalent emergence of it throughout the observed interactions with objects.

Energy (6\%) is another physical concept that was present constantly in the ways children manipulated and interacted with objects, and once again, the present analysis focused on those cases where the phenomenon was central in children's play behaviors. Rushaan and Bradley explored both potential and kinetic energy as they played with marbles going down a cardboard ramp that they constructed in their classroom (this was referred to as the "marble run"). Rushaan puts the marble at the top of the ramp and lets it go down the ramp. He follows the marble with his eyes as it goes down the ramp, across the carpet, and eventually stops. He runs 
after it and comes back to the ramp with marble in hand and lets the marble go down again and runs after it. As Rushaan places the marble at the top of the ramp, he makes sure the marble is on the very edge before letting it go. Bradley joins Rushaan and they both take turns putting their marbles on the ramp, letting it go, and running after it. On one of Rushaan's turns, Bradley puts his hand halfway down the ramp and stops the marble's downward motion. Rushaan pushes the marble with his hand to the end of the ramp. Bradley puts two marbles at the top of the ramp and let's them both go down. "Let's race. I go in front," he tells Rushaan. Bradley lets four and then tree marbles of different sizes go down at a time. Their play continues, letting different marbles go down the ramp until they are called for snack time.

In the excerpt, Bradley and Rushaan tested both, the potential energy of the marble at different points on the ramp as well as the kinetic energy of the moving marble (that eventually stopped due to friction). This experience of experimenting with potential and kinetic energy was also commonplace when children played with the trains and made them go up and down bridges along the tracks.

During these experiences with energy, children also encountered forces (15\%), their own as they pushed an object, like the marble, or gravity, as they observed the pull of gravity acting on the marble as it came down a ramp. They experienced their force acting on handles and knobs that then propelled or initiated motion. For example, at School A, children had access to a play windmill as part of their train set that had a large red handle used to make the windmill go. Children appeared fascinated by the experience of making the windmill turn as a response of their force pushing down on the handle. They would walk by the windmill and pump the handle several times as they moved around in their play space, sometimes stopping to pay close attention to their actions on the windmill and others only stopping briefly to experience the action of pushing down on the lever to make the motion. The important aspect to note here is that through their play, children had a genuine and compelling interest in exploring the phenomenon of using their own force to change the motion of an object. 
Children also encountered the force of gravity ( $9 \%)$, not only as they saw marbles or trains going down ramps, but also as they managed it when building block structures. As they carefully placed one block on top of the other and tried to build vertically, their structures often fell, and as described above, children took on the problem-solving challenge of figuring out how to make their structure stand. Addressing this challenge took (at least) an implicit notion of how gravitational pull acted on their structure in order to build a tower or castle that would stand, as illustrated in the next excerpt. ${ }^{10}$

Mackenzie, Isabel, and Casey pull out wooden blocks and start building. Mackenzie grabs curveshaped blocks and puts them together, making three tubes of different sizes that she calls towers.

"Let's make one big one...but now can we stack them up like a big one?" asks Isabel referring to the smaller towers Mackenzie built. "Let's make one big tower...not like these two," Isabel repeats. Isabel and Mackenzie stack up the curved pieces and connect them to the rest of the castle. "Hey, that's what you just made, Mackenzie," Casey compares the tower Mackenzie and Isabel made with the curved blocks to a picture of a turret in a book on castles sitting out on a bench. Mackenzie places two flat pieces on the turret and as she does the turret collapses. "We can fix it. I know how to fix it guys. Don't worry. I built this, I can fix it," says Mackenzie and she immediately begins to rebuild the structure and Isabel joins her. They are both very careful to line up the thin edges of the curved blocks so they won't fall again, although they continue to struggle to keep all the pieces up. Once they are able to keep the turret structure up, Mackenzie places the flat pieces on top and adds a cone. Mackenzie, Isabel, and Oscar build two structures with rectangular blocks around the turret to keep it from falling. "Help us stack," says Mackenzie, inviting others to help build the supporting structures around the turret to keep it stable. "That might fall. Do not touch it," warns Mackenzie as Sophia joins the building party. The teacher asks Mackenzie what the structures around the turret will do, and Mackenzie responds, "It's going to make it stay up." Sophia adds one more block on top of the turret, but Isabel nervously says, "No! We're all done, Sophia," apparently nervous that the block will make the structure topple over. Mackenzie reasons, "We can have that. We just need to make it balance. [She adds another block on the other side of the turret.] Can I please have two more bricks? [She adds them to the turret.] See it's balancing," as she places two piece. "But it will fall over. It has a lot of heavy weight," says Isabel still nervous. Mackenzie adds a few more pieces before the turret is declared finished and the children focus on building another area of the castle.

Aside from working against gravity, the children's careful building behaviors required that children take special note of how the different blocks fit together and balanced, making sure that there was an even distribution of the weight to maintain their structure upright and steady.

\footnotetext{
${ }^{10} \operatorname{Hood}(1995,1998)$
} 
The way Mackenzie, Isabel, Casey, Oscar, and Sophia navigated the task of building and maintaining the castle turret illustrates the complexity of their play. They enacted spatialmathematical, problem-solving, and planning and executing behaviors and had to engage with physical phenomena like gravity and balance (11\%) (as well as mass and weight, which Isabel brought up spontaneously but were not codes that were used in the present study).

Another physical concept that children also encountered in their play was tension (4\%). Their interactions with tension often involved using a rope or string to pull on another object. These interactions were, at times subtle, as children pulled magnets up the crane or explored the properties of a pulley by pulling a thin rope back and forth on a wheel. In each of these cases, it was the tension created by the stretching of the ropes that allowed children to manipulate the objects the way they wanted. Other times, children's manipulation of tension was more obvious and purposeful. For example, Oscar created a tight rope that served as a passage for pirate dolls by attaching a rope from a ship to an island.

"Hook onto the island," says Oscar and uses the anchor to connect the ship to the island piece with a rope. He slowly moves the island away from the ship to stretch the rope enough to have a taut rope. Casey walks a doll on the rope saying, "I can walk on a high wire."

Like in other situations illustrated thus far, Oscar had sufficient implicit knowledge of tension to inform the way he manipulated the objects to enact a desired play scenario. Interestingly, Casey also demonstrated awareness of the phenomenon of tension to recognize that the tension she was observing and experiencing in her play was akin to the tension of a high wire.

\section{Physics Concepts: Simple Machines}

Simple machines (e.g., levers, pulleys, ramps and inclined planes) made up a special category of physical phenomena that children encountered during object play. Simple machines help to change the direction of force or multiply force to make work easier and serve as the basic 
building blocks of more complex objects we use on a daily basis (for example, a door on hinges works as a lever and a doorknob is an example of a wheel and axle). Basic physical concepts such as force, work, distance, and energy are illustrated by simple machines, and children in this study demonstrated that they were familiar with these mechanisms and incorporated them seamlessly in their play.

For example, as Mackenzie and Isabel continued to build the block castle described above, Mackenzie had a question and an idea, "How can wheelchairs get in? We need a ramp to get up!" This puzzle prompted her not only to explore the idea of ramps and inclined planes (9\%) but to enact her understanding to solve a challenge she had identified.

Mackenzie looks at the blocks she has available on the shelf and picks two triangular blocks that have just the right shape to serve as ramps. She tests out a couple of positions until she finds the position that aligns the ramp along the castle wall. She places one block on either side of the wall. "Castles are for everyone," Mackenzie concludes, indicating that she has addressed the accessibility issue.

Mackenzie's solution required the implicit understanding of ramps and how they are used. She was not only familiar with the idea that ramps are used for wheelchair access - although it is surprising that she was able to see the parallel between her everyday experiences and her play experiences - but she was also able to test and recognize the block shape that would provide just the right ramp access to the castle. Children also built their own ramps and tested the incline to allow for the desired outcome. Bradley used wooden blocks to position the cardboard ramp at just the exact incline he wanted for his marble run.

Bradley is building a new marble run by using wooden blocks and placing the cardboard ramp on them. At first, the ramp extends out flat and the marble does not go very far. The ramp falls. As Bradley rebuilds the ramp, he uses blocks to produce an incline and then adds more blocks to one end to make the incline steeper. He lets go of the marble on one end and celebrates when the marble goes all the way through. He says, "I'm trying to figure this out," as he continues adding and removing blocks to the structure. 
Bradley encountered the concept of ramps and inclined planes and actively manipulated his ideas about the principles of ramps to build a marble run that would work to his satisfaction, again illustrating that his implicit notions informed his building, planning and executing, and problemsolving behaviors.

Children also had opportunities to experience pulleys (5\%) as was described earlier in the case of Emma and as is illustrated further in Casey's play with a toy crane.

Casey takes the crane and turns the knob to put the rope down. She connects the magnet at the end of the rope to a train and pulls it up by turning the knob. She says, "Look, I pulled it up," as the rope and train attached to it come up.

As they observed the trains coming up and down on the crane, children had visual evidence of the principle of a pulley to ease the movement of the rope (not to mention the principle of magnetism). The crane also represented two other simple machines: gears (working as an internal mechanism that connected the knob, the pulley, and the string) and wheel and axle (enabling children to turn the knob). Because gears were nonobvious mechanisms in most cases observed, this category was not analyzed systematically given that it was unlikely that children would have visual or direct access to the gears. The concept of wheel and axle (10\%), on the other hand, was present in components of various objects that children could manipulate, including knobs and cranks that they could turn to make the object work. One particularly interesting instance of wheel and axle observed in both schools was a turntable in the train set that allowed children to change the direction of a train without having to lift it off the tracks. Not only were children quite adept at manipulating the wheel and axle that allowed them to move the train in a certain direction, but they also had the sense to place the turntable in an appropriate location (e.g., at the end of a train track or at an intersection) where it would be most useful. 
Levers $(5 \%)$ were also present as components of objects, such as handles, and were employed along with other simple machines, like wheel and axle, to operate more complex machines, such as a toy crane. They were also present as a drawbridge on hinges or as a seesaw that children manipulated. What stood out about children's manipulations of levers and other simple machines was the ease with which children operated them. Very few times did children look perplexed by a machine in their classroom (except for when children encountered new objects, such as Emma's first encounter with a new pulley toy in her classroom). For the most part, children were familiar with how objects in their classrooms were used and spent their time exploring the many ways they could employ them in their play. They tested the limits of the machine's features - by moving the drawbridge up and down or testing the location of the fulcrum on a seesaw, for instance - with the nonchalance of expert users.

\section{Complex Objects and Affordances}

As is apparent in the descriptions of children's behavior sequences and the physical phenomena that emerged during object play, object features were closely linked to how objects were used and what concepts they exemplified. Magnet trains could be connected and provided children with the opportunity to experience and manipulate magnetism (repelling and attracting forces); blocks could be stacked and aligned permitting children to build structures and encounter concepts like gravity and balance. Each object had particular properties that informed children's play behaviors, but perhaps most interesting were complex objects that were rich with affordances that children could explore and manipulate. Certain objects or structures stood out as unique examples of the role of affordances because of the multiple parts and access points that facilitated contact with various physical principles. The toy crane was an especially salient example of this. Both schools had a crane that had a knob to wind or unwind a string; a pulley- 
like system that enabled the string to come up and down the crane platform; and a magnet at the end of the string where they could connect magnetic train cars and pull them up. Given its multiple parts and mechanisms, the crane represented concepts like pulley, wheel and axle, magnetism, and tension. At any given point, children could explore one aspect of the pulley and its corresponding physical properties or play with all of them in tandem, seeing the interaction among the physical principles.

Another interesting case was the marble run observed in School B but present in both schools. ${ }^{11}$ A unique aspect of the marble run was that it could be constructed by children to vary along a number of features - length, angle, inclination, direction — that children manipulated and explored as they added pieces to it or utilized different marbles that varied in size. The flexibility of the different parts of the marble run engaged children in planning and executing, spatialmathematical, and problem-solving behaviors as they used blocks and other materials in their classrooms to explore (often elaborate) variations on the design of the marble run. And although at its most basic this contraption entailed children dropping a marble at one end and seeing it go down and across the carpet, it provided plenty of opportunities for children to explore principles of inclined planes and ramps, energy, gravity, and force.

\section{School Differences}

Because the emphasis of this study was not on comparing the two schools but rather representing the different opportunities that preschoolers may encounter as they play with objects, the results focus on the aggregate of observations across the two research sites.

However, some relevant differences between the schools are worth mentioning to illustrate how

\footnotetext{
${ }^{11}$ School B had two versions of the marble run: one, child-sized version was constructed using two long cardboard ramps that could be propped up against bookshelves and wooden blocks; the other version involved miniature wooden ramps that were connected and propped up using blocks. School A had the smaller version of the marble run available but children were not observed using it during the study.
} 
much the affordances of the objects and the pedagogical environment appeared to interact with children's play experiences.

In many cases, the frequencies of different actions or concepts in each classroom were similar between schools; that said, noteworthy differences did exist in a number of categories and these seemed related to differences in the objects present and the nature of object play observed in each classroom (see Table 1). For example, exploratory behaviors were observed to a greater extent in School B (13\%) than School A (6\%) and this seemed to occur as a result of a teacher introducing a new object (a pulley system) to the play space in School B, which engaged children in investigatory behaviors that children did not tend to demonstrate with more familiar objects. Likewise, there were more instances of planning and executing behaviors in School A (43\%) than School B (28\%) and the difference appeared related to the fact that three School A sessions were dedicated to playing and building almost exclusively with train tracks or blocks while train tracks were only observed during one session and blocks were available as one of several choice centers in School B.

Differences among the schools in the frequency of physical concepts that emerged are explained in a similar way. The higher frequency of encounters with magnetism in School A $(30 \%)$ was mostly driven by the extensive experiences children had with magnetic trains compared to the relative lower frequency in School B $(10 \%)$ where trains were available only on one of the observed days. In School B, the higher frequency of energy (13\%), gravity (14\%), and ramps and inclined planes $(17 \%)$ was tied to the presence of the marble run.

Given the responsiveness to children's interests in both schools, it is possible that the differences observed also speak to the kinds of activities and objects that children had an expressed desire to see in their free play. This interaction between children's preferences and the 
pedagogical choices around play is an area worth pursuing in future research. Despite these observed differences, however, the results provide a rich picture of the physical world that emerges through young children's play with objects.

\section{Discussion}

The results described here illustrate the nature of children's behaviors during object play and the myriad opportunities they have to engage with physical phenomena as they manipulate objects within the play context. However, the behaviors and physical concepts presented here are by no means exhaustive. Certain play behaviors and physical phenomena were not included in analyses because they did not emerge as prominent patterns within or between schools. Bouncing or throwing actions, mass and weight concepts, and physical principles involved in playing with water, for example, were certainly observed in children's play but were not frequent, salient, or consistent in the data. The present investigation, thus, provides a picture of the world of possibilities that children have access to during object play to explore physical phenomena and the variety of events and ideas that adults can leverage to introduce young children to science, mathematical, and engineering principles through play.

\section{Pedagogical Context}

Conspicuously missing in the results is an account of teachers' participation in children's play and the pedagogical context that surrounded play experiences. Children were observed during free play and spent much of their time in self-directed play activities; however, teachers and teacher choices, along with the larger school philosophy, resources, and priorities, were ever present in the kinds of play experiences children had access to and engaged in. Because play was valued as a learning tool in both schools, free play opportunities were carefully curated by teachers. Teachers had access to a wealth of materials and, every day, they chose what objects to 
put out on the shelf or carpet with either an implicit or explicit learning goal for children's interactions with these objects. They recognized the opportunities afforded by different objects and made choices based on those perceived provocations. As one teacher in School A described, teachers "intentionally alternate[d]" among objects that would invite instances of learning during play, being careful to attend to and incorporate children's interests. Furthermore, teachers actively supported children's play by managing interactions between children around a given toy or activity, suggesting play narratives that children would incorporate into their object manipulations, modeling play actions with objects, and providing additional props and materials to extend children's play sequences. The teacher from School A explained that from her perspective, “the teacher's role [in play] is critical because you can guide, model, and scaffold but then you have to know when to enter and when to exit [the play interaction]."

The present study did not investigate the relationship between teacher or school characteristics and children's play experiences, but this is likely an area that deserves further research if we are to understand how object play can be utilized to support young children's learning of science concepts. Observations in other school contexts may give a different picture of what kinds of objects, play opportunities, or scientific content are available for children. Bairaktarova, Evangelou, and Bagiati, and Dobb-Oates (2012) found that when asked, "Do you identify and describe the characteristics of simple machines?," 20\% of Head Start teachers interviewed said that they did compared to $80 \%$ of teachers in university-affiliated preschools. Nevertheless, teachers from both school settings who responded affirmatively to this question described providing children with hands-on play experiences with simple machines like gears and ramps and engaging children in conversations about these simple machines. One hypothesis we can draw from existing literature as well as the findings of the present study is that teachers' 
ability to attentively observe children's play and recognize physical concepts that may apply to children's experiences is an important skill to scaffold children in further discovering and learning about these concepts. Citing Siraj-Blatchford (2001), Larsson (2013) explains that, "When children are attentive to the world around them, the teacher's mission is to support their discovery and exploration of scientific phenomena [sic] and to involve them in investigations that allow them to collaborate and talk about science" (p. 379). How teachers can be prepared and supported to enact the instructional moves necessary to draw out the science embedded in play experiences with objects is a research area with important implications for improving preschool curriculum and instruction.

The results also suggest directions to further investigate the link between children's object play and their scientific reasoning. As expressed in the introduction, the results only point to the possible opportunities for learning about physical concepts but they do not demonstrate a relationship between these experiences and the ideas about the physical world children actually learn. Further research will elucidate this potential relationship. For example, a follow up study could investigate whether children's experience playing with objects that afford interactions with certain physical phenomena is related to their ability to describe these scientific concepts or employ this knowledge to solve a behavioral task. A pilot task conducted at the end of the current study investigated whether knowledge of a particular simple machine - a pulley— transferred to a novel situation. Children were asked to help Sarah and Andrew (two play dolls) to get a picnic basket up to their tree house. They were then presented with a variety of materials, including a pulley system that could be used to solve this problem. Pilot data showed that children who had played more extensively with a pulley prior to the presentation of the tree house problem were more likely to choose the pulley system as their first option to help get the 
picnic basket up the tree house. The task is being developed further but the data suggest a possibly meaningful link between the nature of children's manipulation of objects during play and their knowledge and application of physical concepts.

\section{Conclusion}

Whether building a block castle or investigating the seemingly infinite potential of a cardboard box, young children can be found engrossed playing, discovering, and creating with the objects in their environment. The potential of objects to incite children to explore and think about physical phenomena (as they implicitly test friction and gravity, for example) provides an ideal setting to investigate how play might contribute to young children's development of physical knowledge. The present study exemplifies children's early experiences with physical phenomena in everyday play encounters with objects and the possible origins of later scientific conceptions. Further understanding the ways object play is supported in classrooms and how this may be related to children's exercise of scientific thinking can inform how object play can be used as pedagogical tools to introduce STEM into the preschool curriculum. 


\section{References}

Bairaktarova, D., Evangelou, D., Bagiati, A., \& Dobbs-Oates, J. (2012, June). The role of classroom artifacts in developmental engineering. Paper presented at the American Society for Engineering Education Annual Conference, San Antonio, TX.

Bjorklund, D. F., \& Gardiner, A. K. (2010). Object play and tool use: Developmental and evolutionary perspectives. In A. D. Pellegrini (Ed.), The Oxford Handbook of the Development of Play (pp. 153-171). New York, NY: Oxford University Press.

Caldera, Y.M., Culp, A. M., O’Brien, M., Truglio, R. T., Alvarez, M., \& Huston, A. C. (1999). Children's play preferences, construction play with blocks, and visual-spatial skills: Are they related? International Journal of Behavioral Development, 23(4), 855-872.

Callaghan, T., Moll, H., Rakoczy, H., Liszkowski, U., Behne, T., \& Tomasello, M. (2011). Early social cognition in three cultural contexts. Monographs of the Society for Research in Child Development, 76(2), 1-142.

Casey, B. M., Andrews, N., Schindler, H., Kersh, J. E., Samper, A., \& Copley, J. (2008). The development of spatial skills through interventions involving block building activities. Cognition and Instruction, 26(3), 269-309.

Charmaz, K. (2002). Qualitative interviewing and grounded theory analysis. In J. F. Gubrium \& J. A. Holstein (Eds.), Handbook of interview research: Context \& method (pp. 675-694). Thousand Oaks, CA: Sage Publications, Inc.

Cole, M. (1998). Can cultural psychology help us think about diversity? Mind, Culture, and Activity, 5(4), 291-304. 
Cole, M. \& Gajdamaschko, N. (2007). Vygotsky and culture. In H. Daniels, M. Cole, \& J.V. Wertsch (Eds.), The Cambridge Companion to Vygotsky (pp. 193-211). New York, NY: Cambridge University Press.

Cook, C., Goodman, N. D., \& Schulz, L. E. (2011). Where science starts: Spontaneous experiments in preschoolers' exploratory play. Cognition, 120(3), 341-349.

Evangelou, D., Dobbs-Oates, J., Bagiati, A., Liang, S., \& Young Choi, J. (2010). Talking about artifacts: preschool children's explorations with sketches, stories, and tangible objects. Early Childhood Research \& Practice, 12(2). Retrieved 19 March 2014 from http://ecrp.uiuc.edu/v12n2/evangelou.html.

Ferrera, K., Hirsh-Pasek, K., Newcombe, N. S., Golinkoff, R. M., \& Lam, W. S. (2011). Block talk: Spatial language during block play. Mind, Brain, and Education, 5(3), 143-151.

Fox, J. E. (1997). Swinging: What young children begin to learn about physics during outdoor play. Journal of Elementary Science Education, 9(1), 1-14.

Garvey, C. (1990). Play. Cambridge, MA: Harvard University Press.

Gibson, E. J. (2000). Perceptual learning in development: Some basic concepts. Ecological Psychology, 12(4), 295-302.

Gopnik, A. (2012). Scientific thinking in young children: Theoretical advances, empirical research, and policy implications. Science, 337(6102), 1623-1627.

Gopnik A., \& Sobel, D. M. (2000). Detecting blickets: How young children use information about causal powers in categorization and induction. Child Development, 71(5), 12051222.

Gross, C. M. (2012). Science concepts young children learn through water play. Dimensions of Early Childhood, 40(2), 3-11. 
Gur, C. (2011). Physics in preschool. International Journal of Physical Sciences, 6(4), 939-943. Hadzigeorgiou, Y. (2002). A study of the development of the concept of mechanical stability in preschool children. Research in Science Education, 32(3), 373-391.

Henricks, T. (2008). The nature of play. American Journal of Play, 1(2), 157-180.

Hughes, B. (2012). Evolutionary playwork ( ${ }^{\text {nd }}$ Edition). New York, NY: Routledge.

Hutt, C. (1966). Exploration and play in children. Symposia of the Zoological Society of London, $18,61-81$.

Hutt, S.J., Tyler, S., Hutt, C., \& Christopherson, H. (1989). Play, exploration and learning: A natural history of the preschool. New York, NY: Routledge.

Johnson, J. E., Christie, J. F., \& Wardle, F. (2005). Play, development, and early education. Boston, MA: Pearson/A and B.

Kamii, C., \& DeVries, R. (1993). Physical knowledge in preschool education: Implications of Piaget's theory. New York, NY: Teachers College Press.

Kamii, C., Miyakawa, Y., \& Kato, Y. (2004). The development of logico-mathematical knowledge in a block-building activity at ages 1-4. Journal of Research in Childhood Education, 19(1), 44-57.

Kurtus, R. (2014). Levers are simple machines. Retrieved from http://www.school-forchampions.com/machines/levers.htm\#.VDKytVePCnI

Larsson, J. (2013). Children's encounters with friction as understood as a phenomenon of emerging science and as "opportunities for learning." Journal of Research in Childhood Education, 27(3), 377-392. 
Legare, C. H. (2012). Exploring explanation: Explaining inconsistent evidence informs exploratory, hypothesis-testing behavior in young children. Child Development, 83(1), 173-185.

Legare, C. H. (2014). The contributions of explanation and exploration to children's scientific reasoning. Child Development Perspectives, 8(2), 101-106.

Legare, C.H., Mills, C.M., Souza, A.L., Plummer, L.E., \& Yasskin, R. (2013). The use of questions as problem-solving strategies during early childhood. Journal of Experimental Child Psychology, 114(1), 63-76.

Lillard, A. S., Lerner, M. D., Hopkins, E. J., Dore, R. A., Smith, E. D., \& Palmquist, C. M. (2013). The impact of pretend play on children's development: A review of the evidence. Psychological Bulletin, 139(1), 1-34.

Maxwell, J.A. (2005). Qualitative research design: An interactive approach ( $2^{\text {nd }}$ Edition). Thousand Oaks, CA: SAGE Publications.

Park, B., Chae, J-L., \& Boyd, B. F. (2008). Young children's block play and mathematical learning. Journal of Research in Childhood Education, 23(2), 157-162.

Pellegrini, A. D. (2009). The role of play in human development. New York, NY: Oxford University Press.

Pepler, D. J., \& Ross, H. S. (1981). The effects of play on convergent and divergent problem solving. Child Development, 52(4), 1202-1210.

Piaget, J. (1930). The child's conception of physical causality. London: K. Paul, Trench, Trubner \& Company Limited.

Power, T. G. (2000). Play and exploration in children and animals. Mahwah, N.J.: L. Erlbaum Associates. 
Samara, J. and Clements, D. H. (2009). Early childhood mathematics education research: Learning trajectories for young children. New York, NY: Routledge.

Sawyer, R. K. (2002). The new anthropology of children, play, and games. Reviews in Anthropology, 31(2), 147-164.

Schulz, L., \& Bonawitz, E. B. (2007). Serious fun: Preschoolers play more when evidence is confounded. Developmental Psychology, 43(4), 1045-1050.

Schulz, L., Gopnik, A., \& Glymour, C. (2007). Preschool children learn about causal structure from conditional interventions. Developmental Science (special section on Bayesian and Bayes-Net approaches to development), 10(3), 322-332.

Schwartzman, H. B. (1976). The anthropological study of children's play. Annual Review of Anthropology, 5, 289-328.

Singer, D. G., Golinkoff, R. M., \& Hirsh-Pasek, K. (2006). Play=learning: How play motivates and enhances children's cognitive and social emotional growth. New York, NY: Oxford University Press.

Smith, P. K. (2010). Children and play. Malden, MA: Wiley-Blackwell.

Sobel, D. M., \& Sommerville, J. A. (2010). The importance of discovery in children's causal learning from interventions. Frontiers in Developmental Psychology, 1, 176-183.

Stoll, J., Hamilton, A., Oxley, E., Eastman, A. M., \& Brent, R. (2012). Young Thinkers in Motion: Problem Solving and Physics in Preschool. Young Children, 67(2), 20-26.

Sylva, K., Bruner, J. S., \& Genova, P. (1976). The role of play in the problem-solving of children 3-5 years old. In J. S. Bruner, A. Jolly, \& K. Sylva (Eds.), Play, its role in development and evolution (pp. 244-257). New York, NY: Basic Books. 
Trawick-Smith, J. (2010). Drawing back the lens on play: a frame analysis of young children's play in Puerto Rico. Early Education \& Development, 21(4), 536-567.

Turkle, S. (2007). Evocative objects: things we think with. Cambridge, MA: MIT Press.

Van Meeteren, B., \& Zan, B. (2010). Revealing the work of young engineers in early childhood education. Early Childhood Research and Practice. Collected Papers from the SEED (STEM in Early Education and Development) Conference. Retrieved from http://ecrp.uiuc.edu/beyond/seed/zan.html

Vosniadou, S. (2002). On the nature of naïve physics. In M. Limón \& L. Mason (Eds.), Reconsidering conceptual change: Issues in theory and practice (pp. 61-76). Norwell, MA: Kluwer Academic Publishers.

Wilkening, F., \& Cacchione, T. (2010). Children's intuitive physics. In U. Goswami (Ed.), The Wiley-Blackwell handbook of childhood cognitive development (pp. 473-496). Malden, MA: Wiley-Blackwell.

Zimmerman, C. (2000). The development of scientific reasoning skills. Developmental Review, 20(1), 99-149. 


\section{Appendix A}

Coding scheme including code names, descriptions, and examples for behavior sequences and physics concepts.

\begin{tabular}{|c|c|c|}
\hline \multicolumn{3}{|c|}{ Behavior Sequences } \\
\hline Code & Description & Example $^{12}$ \\
\hline Spatial-Mathematical Behaviors & $\begin{array}{l}\text { The child manipulates objects paying } \\
\text { attention to their spatial configuration, } \\
\text { position, direction/orientation, proportion, or } \\
\text { alignment. This may include, constructing, } \\
\text { fitting, or connecting things together. }\end{array}$ & $\begin{array}{l}\text { Child is playing with train tracks and } \\
\text { struggles to fit them together. She takes the } \\
\text { previous tracks apart and puts them back } \\
\text { together. }\end{array}$ \\
\hline Problem-Solving Behaviors & $\begin{array}{l}\text { The child encounters a situation that requires } \\
\text { figuring out what needs to change or what } \\
\text { needs to be fixed in order to proceed with the } \\
\text { play sequence. The child is essentially trying } \\
\text { to figure out a solution. }\end{array}$ & $\begin{array}{l}\text { Child is trying to fit a train sideways through } \\
\text { a mountain tunnel but it doesn't fit that way. } \\
\text { The child switches the orientation of the train } \\
\text { and now it goes through. }\end{array}$ \\
\hline Exploratory Behaviors & $\begin{array}{l}\text { The child engages in trying different actions } \\
\text { with the same set of toys in somewhat of a } \\
\text { trial and error, iterative fashion. The child is } \\
\text { exploring different ways of using a object or } \\
\text { different features of the object. Features refer } \\
\text { to surface, physical characteristics that } \\
\text { children can explore. What the object is made } \\
\text { of and its different parts. }\end{array}$ & $\begin{array}{l}\text { Child is playing with a pulley and she places } \\
\text { the string over a wheel, and then wraps it } \\
\text { around to a second wheel. The string falls off, } \\
\text { and she replaces it on the first wheel again. } \\
\text { She pulls up and down on the string around } \\
\text { the wheel. She tries a new orientation of } \\
\text { string on the pulley. Similar behaviors } \\
\text { continue. }\end{array}$ \\
\hline Planning and Executing Behaviors & $\begin{array}{l}\text { The child lays out a plan to play with or } \\
\text { manipulate the objects in a certain way and } \\
\text { follows through. This planning and executing } \\
\text { may be overtly described by the child or } \\
\text { evident in the child's actions. }\end{array}$ & $\begin{array}{l}\text { Child announces she will build a bridge and } \\
\text { then works diligently to line up wooden blocks } \\
\text { to build the bridge. Or a child is building a } \\
\text { track and comes back to it a few minutes later } \\
\text { and resumes building. Or a child gets up to } \\
\text { find a piece and then returns to their project. } \\
\text { Or they pause like they're trying to figure out } \\
\text { what to do next. }\end{array}$ \\
\hline
\end{tabular}

\footnotetext{
${ }^{12}$ Note that examples are hypothetical but are informed by real observations.
} 


\begin{tabular}{|c|c|c|}
\hline \multicolumn{3}{|c|}{ Physics Concepts } \\
\hline Magnetism & $\begin{array}{l}\text { The child utilizes, manipulates, tests, } \\
\text { explores, explains, or otherwise encounters } \\
\text { magnets during play. }\end{array}$ & $\begin{array}{l}\text { Child creates a long line of trains connected } \\
\text { by magnets and figures out how to pull the } \\
\text { line without disconnecting the trains. }\end{array}$ \\
\hline Gravity & $\begin{array}{l}\text { The child encounters, manipulates, tests, } \\
\text { explains, or otherwise explores gravity during } \\
\text { play. Gravity refers to the "natural } \\
\text { phenomenon by which all physical bodies } \\
\text { attract each other. Gravity gives weight to } \\
\text { physical objects and causes them to fall } \\
\text { toward the ground when dropped."13 }\end{array}$ & $\begin{array}{l}\text { Child holds a ball and drops it from different } \\
\text { heights and watches as the ball falls to the } \\
\text { ground. Or, the child is building a tower and } \\
\text { then tips over the top block to see it fall. }\end{array}$ \\
\hline Friction & $\begin{array}{l}\text { The child encounters, manipulates, tests, } \\
\text { explains, or otherwise explores friction during } \\
\text { play. Friction refers to the "force resisting the } \\
\text { relative motion of solid surfaces, fluid layers, } \\
\text { and material elements sliding against each } \\
\text { other." The most common type of friction } \\
\text { during object play will likely be dry friction, } \\
\text { which "resists relative lateral motion of two } \\
\text { solid surfaces in contact."13 This can include } \\
\text { activities where the child shuffles, slides, } \\
\text { pushes, pulls, or spins objects. }\end{array}$ & $\begin{array}{l}\text { Child pulls trains along the carpet and } \\
\text { experiences a different resistance on the } \\
\text { carpet than she did on the train tracks. }\end{array}$ \\
\hline Tension & $\begin{array}{l}\text { The child encounters, manipulates, tests, } \\
\text { explains, or otherwise explores tension during } \\
\text { play. Tension refers to "a force related to the } \\
\text { stretching of an object." } 13\end{array}$ & $\begin{array}{l}\text { Child attaches a rope to one object and then } \\
\text { pulls it and attaches it to another object to } \\
\text { create a tightrope. }\end{array}$ \\
\hline Balance & $\begin{array}{l}\text { The child encounters, manipulates, tests, } \\
\text { explains, or otherwise explores balance during } \\
\text { play. Balance refers to "an even distribution } \\
\text { of weight enabling something to remain } \\
\text { upright and steady."15 }\end{array}$ & $\begin{array}{l}\text { Child builds a block tower and carefully } \\
\text { places the blocks on top of one another as she } \\
\text { builds vertically, being careful not to knock } \\
\text { over the structure. Or, the child creates an } \\
\text { actual balance by putting two objects on }\end{array}$ \\
\hline
\end{tabular}

\footnotetext{
${ }^{13}$ To make code descriptions accessible and intuitive for coders, language from Wikipedia entries for several of the physical concepts was used. This language was crosschecked with existing literature describing these concepts in preschool settings.

${ }^{14}$ Larsson (2013)

${ }^{15}$ To make the Balance code description accessible and intuitive for coders, language from the Google definition for this physical concept was used. This language was crosschecked with existing literature describing this concept in the preschool setting.
} 


\begin{tabular}{|c|c|c|}
\hline & & $\begin{array}{l}\text { either side of a flat plank and trying to } \\
\text { distribute the weight evenly. }\end{array}$ \\
\hline Forces & $\begin{array}{l}\text { The child encounters, manipulates, tests, } \\
\text { explains, or otherwise explores concepts of } \\
\text { force during play. Force refers to "any } \\
\text { interaction which tends to change the motion } \\
\text { of an object. Forces are also described as a } \\
\text { push or pull on an object. They can be due to } \\
\text { phenomena such as gravity, magnetism, or } \\
\text { anything that might cause a mass to } \\
\text { accelerate."13 }\end{array}$ & $\begin{array}{l}\text { Child might test the principle that there are } \\
\text { equal but opposite forces at play by leaning } \\
\text { two long blocks against each other and } \\
\text { creating a triangular structure. Or, the child } \\
\text { applies force on a moving marble to make it } \\
\text { go faster. }\end{array}$ \\
\hline Energy & $\begin{array}{l}\text { The child encounters, manipulates, tests, } \\
\text { explains, or otherwise explores concepts of } \\
\text { kinetic and potential energy during play. } \\
\text { Energy refers to "a property of objects, } \\
\text { transferable among them via fundamental } \\
\text { interactions, which can be converted in form } \\
\text { but not created or destroyed." This may } \\
\text { include "the kinetic energy of a moving } \\
\text { object" or "the potential energy stored by } \\
\text { virtue of the position of an object."." }\end{array}$ & $\begin{array}{l}\text { Child holds a train on top of a hill and then } \\
\text { lets it go making it roll down the hill. Or, } \\
\text { child holds a marble on top of a ramp and } \\
\text { then lets it go. }\end{array}$ \\
\hline \multicolumn{3}{|c|}{ Physics Concepts: Simple Machines } \\
\hline Simple Machines: Levers & $\begin{array}{l}\text { The child utilizes, manipulates, tests, } \\
\text { explores, explains, or otherwise encounters } \\
\text { levers during play. This includes using or } \\
\text { building seesaws and handles. "A lever is a } \\
\text { simple machine that allows you to gain a } \\
\text { mechanical advantage in moving an object or } \\
\text { in applying a force to an object." "A lever is } \\
\text { a machine consisting of a beam or rigid rod } \\
\text { pivoted at a fixed hinge, or fulcrum."13 }\end{array}$ & $\begin{array}{l}\text { Child uses the handle on a play windmill to } \\
\text { make the windmill spin. }\end{array}$ \\
\hline Simple Machines: Wheel and Axle & $\begin{array}{l}\text { The child utilizes, manipulates, tests, } \\
\text { explores, explains, or otherwise encounters } \\
\text { knobs during play. "Wheel and axle in a }\end{array}$ & $\begin{array}{l}\text { Child turns a knob to open up a door in a play } \\
\text { castle. }\end{array}$ \\
\hline
\end{tabular}

\footnotetext{
${ }^{16}$ Kurtus (2014)
} 


\begin{tabular}{|c|c|c|}
\hline & $\begin{array}{l}\text { simple machine consisting of a wheel (or } \\
\text { crank) and an axle that turn on the same axis. } \\
\text { Steering wheels, doorknobs, and screwdrivers } \\
\text { are wheel-and-axle devices." } 17\end{array}$ & \\
\hline Simple Machines: Pulleys & $\begin{array}{l}\text { The child utilizes, manipulates, tests, } \\
\text { explores, explains, or otherwise encounters } \\
\text { pulleys during play. A pulley refers to "a } \\
\text { wheel on an axle that is designed to support } \\
\text { movement and change of direction of a cable } \\
\text { or belt along its circumference. Pulleys are } \\
\text { used in a variety of ways to lift loads, apply } \\
\text { forces, and to transmit power."13 }\end{array}$ & $\begin{array}{l}\text { Child plays with a crane, which uses a string } \\
\text { around a wheel to pull a toy car up. }\end{array}$ \\
\hline $\begin{array}{l}\text { Simple Machines: Ramps and Inclined } \\
\text { Planes }\end{array}$ & $\begin{array}{l}\text { The child utilizes, manipulates, tests, } \\
\text { explores, explains, or otherwise encounters } \\
\text { ramps during play. "An inclined plane is a flat } \\
\text { supporting surface tilted at an angle, with one } \\
\text { end higher than the other, used as an aid for } \\
\text { raising or lowering a load."13 }\end{array}$ & $\begin{array}{l}\text { Child builds a ramp to make it "easier" for } \\
\text { play dolls to access the castle. Or, child tests } \\
\text { out the angle of a ramp to ensure that her } \\
\text { marble goes to the spot she desires. }\end{array}$ \\
\hline
\end{tabular}

\footnotetext{
${ }^{17}$ To make the Wheel and Axle code description accessible and intuitive for coders, language from the howstuffworks entry for this physical concept was used. This language was crosschecked with existing literature describing this concept in the preschool setting.
} 